\title{
Lisbon Symbol Database (LSD): Subjective norms for 600 symbols
}

\author{
Marília Prada $^{1}$ - David Rodrigues ${ }^{1,2} \cdot$ Rita R. Silva $^{3} \cdot$ Margarida V. Garrido $^{1}$
}

Published online: 15 August 2015

(C) Psychonomic Society, Inc. 2015

\begin{abstract}
This article presents subjective rating norms for a new set of 600 symbols, depicting various contents (e.g., transportation, technology, and leisure activities) that can be used by researchers in different fields. Symbols were evaluated for aesthetic appeal, familiarity, visual complexity, concreteness, valence, arousal, and meaningfulness. The normative data were obtained from 388 participants, and no gender differences were found. Descriptive results (means, standard deviations, and confidence intervals) for each symbol in each dimension are presented. Overall, the dimensions were highly correlated. Additionally, participants were asked to briefly describe the meaning of each symbol. The results indicate that the present symbol set is varied, allowing for the selection of exemplars with different levels on the seven examined dimensions. This set of symbols constitutes a tool with potential for research in different areas. The database with all of the symbols is available as supplemental materials.
\end{abstract}

Keywords Symbols $\cdot$ Normative data $\cdot$ Subjective ratings $\cdot$ Aesthetic appeal $\cdot$ Familiarity $\cdot$ Visual complexity . Concreteness $\cdot$ Valence $\cdot$ Arousal $\cdot$ Meaningfulness

Electronic supplementary material The online version of this article (doi:10.3758/s13428-015-0643-7) contains supplementary material, which is available to authorized users.

Marília Prada

mariliaprada@iscte.pt

1 Department of Social and Organizational Psychology, ISCTE-IUL, CIS-IUL, Av. das Forças Armadas, Office AA110, 1649-026 Lisbon, Portugal

2 Goldsmiths, University of London, London, UK

3 William James Center for Research, ISPA-Instituto Universitário, Lisboa, Portugal
Symbols are everywhere. Just think about a typical day. At home we can find them in the box of cereal we eat for breakfast (e.g., a brand logo and the recyclable package symbol). On our way to work, they are on the car dashboard (e.g., the fuel symbol) and on the road (e.g., traffic signs). Upon arrival at the office, they are all over our computer screen (e.g., software and Internet icons). Symbols are used to quickly and easily communicate a variety of information, such as directions, places, and actions, in both the physical and virtual worlds (Tijus, Barcenilla, Lavalette, \& Meunier, 2007).

What defines a symbol? From the semiotic standpoint, a sign constitutes a part of a triadic relation composed of an object (the referent), a sign, and an interpretant (connecting the previous elements). Based on the relationship between a sign and its object, three categories are defined: (a) For icons, the relationship is based on similarity (e.g., caricature); (b) for indexes, the relationship is based on a real direct connection (e.g., fingerprint); and (c) for symbols, the relationship is based on an arbitrary convention (e.g., a national flag; for reviews on this matter, see Harbeck, 2011; McDougall, Curry, \& de Bruijn, 1999; Nakamura \& Zeng-Treitler, 2012). However, as was noted by Nakamura and Zeng-Treitler, the distinction between different types of signs is not always clear, and authors often redefine these concepts in an attempt to clarify the stimuli they are referring to. In line with McDougall and colleagues (1999), we use the term "symbol" to refer not only to symbols, but also to icons, pictograms, and signs. Symbols are generally used to replace written indications and instructions regarding regulatory, mandatory, warning, and prohibitory information. They are particularly useful in situations that require information to be processed quickly and when perceivers have limited linguistic ability (e.g., those with low levels of literacy or nonnatives; for a review, see Tijus et al., 2007).

Considering the importance and extensive use of symbols in our daily life, as well as in our scientific endeavors, the goal 
of the present article is to provide normative ratings for a broad set of 600 symbols that can be used by researchers in different fields. The publication of norms for sets of stimuli is of the utmost importance for the scientific community, because it provides validated materials that can be used in different experimental paradigms, particularly when the manipulation (and strict control) of stimulus characteristics is required. The proliferation of such publications has come, therefore, as no surprise. Already in 1999, Proctor and Vu provided an index of norms and ratings published in the Psychonomic Society journals between 1965 and 1999, which included 142 sets, mostly of verbal materials. We can also find normative data for a variety of visual stimuli, from simple line-drawing sets (e.g., Cycowicz, Friedman, Rothstein, \& Snodgrass, 1997; Snodgrass \& Vanderwart, 1980) to complex real-life pictures depicting a broad range of contents, such as people, animals, or objects (e.g., Dan-Glauser \& Scherer, 2011; Lang, Bradley, \& Cuthbert, 2008; Marchewka, Zurawski, Jednorog, \& Grabowska, 2013; Prada, Cunha, Garcia-Marques, \& Rodrigues, 2010). A considerable number of databases with normative ratings of human faces are also available in the literature (e.g., Ebner, Riediger, \& Lindenberger, 2010; Goeleven, De Raedt, Leyman, \& Verschuere, 2008; Langner et al., 2010). For symbols, however, the amount of published resources is more limited. One important exception is McDougall and colleagues' (1999) set of 239 symbols. This set comprises symbols categorized according to the contexts in which they are used, namely computers (e.g., software packages), traffic and public information (e.g., road signs), industrial (e.g., machinery), and household goods (e.g., domestic appliances). In this study, the authors presented norms for familiarity, complexity, concreteness, meaningfulness and semantic distance for each symbol. The same set was subsequently tested with regard to aesthetic appeal (McDougall \& Reppa, 2008).

The present article describes a database of 600 new symbols. Each symbol was evaluated in five of the dimensions used by McDougall (McDougall et al., 1999; McDougall \& Reppa, 2008): familiarity (subjective frequency), visual complexity, concreteness, aesthetic appeal and meaningfulness. Additionally, we added two new dimensions - valence and arousal — and collected data regarding the meaning attributed to each stimulus. The motivation for developing norms for this new set, entirely different from existing ones (e.g., McDougall et al., 1999), was twofold. First, we wanted to test a broader range of stimuli in order to have a more diverse pool from which different subsets can be selected. For instance, we included symbols that were recently introduced in our lives such as gadgets and social media. Second, the current aesthetics and visual appearance of symbols is not the same as it was 16 years ago. Thus, McDougall and colleagues' (1999) symbol set may appear somewhat outdated in the present days.
Normative ratings for a large set of symbols constitute a tool with potential for research in different areas. For example, this type of stimuli is useful for researchers using mere exposure (i.e., repeated exposure to Chinese-like characters leads to more positive attitudes, Zajonc, 1968) or affective priming paradigms (e.g., ideographs are evaluated more positively when preceded by happy vs. angry faces; Murphy \& Zajonc, 1993). Our set may offer alternatives in material selection beyond the foreign language characters typically used (e.g., for Greek, see Garcia-Marques, 2005; for Japanese, see Hess, Waters, \& Bolstad, 2000; Rotteveel \& Phaf, 2004). Symbols have also been used to prime concepts (see Bargh \& Chartrand, 2000). For example, the "dollar" symbol (embedded in the background of a web page) activates a specific product attribute (i.e., price), increasing its weight in a subsequent decision-making task (Mandel \& Johnson, 2002). Other possible uses include the examination of the effects of visual context on memory (Palma, Garrido, \& Semin, 2014), of the processes involved in icon comprehension (e.g., McDougall $\&$ Isherwood, 2009), theories of attention and visual search tasks (e.g., McDougall, Tyrer, \& Folkard, 2006), the refinement of visual process models (e.g., Figl, Mendling, \& Strembeck, 2013), and neuroimaging studies examining how icons are processed in the brain (e.g., Huang, Bias, \& Schnyer, 2015). Furthermore, this database is also likely to be useful in more applied domains, namely the effective communication of traffic sign messages to road users (e.g., Oh, Rogoff, \& Smith-Jackson, 2013), the comprehension and use of pharmaceutical pictograms (e.g., Montagne, 2013), warning symbol comprehension (e.g., Lesch, Powell, Horrey, \& Wogalter, 2013), cross-cultural comparisons of the use of symbols to convey warnings and instructions (e.g., Blees \& Mak, 2012; Chan \& Ng, 2012), and the design of icons that are suitable to specific populations, such as the elderly (e.g., Leung, McGrenere, \& Graf, 2011) or preschoolers (Chiu, Koong, \& Fan, 2012).

In sum, the present symbol set can provide standardized ready-to-use experimental material to Portuguese researchers. It should be noted that this type of norms can be culture-specific. For instance, Snodgrass and Vanderwart's (1980) stimulus set, originally evaluated by a North American sample, has been validated in several countries and cultures, including Portugal, Italy, Russia, and Japan (for a review, see Wang, Chen, \& Zhu, 2014). Other international normative stimulus sets, such as the Affective Norms for English Words (ANEW; Soares, Comesaña, Pinheiro, Simões, \& Frade, 2012), International Affective Digitized Sounds (IADS; Soares et al., 2013), and International Affective Picture System (IAPS; Soares et al., 2014) have also recently been adapted to the Portuguese population. Likewise, the present symbol set is also readily available for cross-validation in other countries.

In the following section, we provide an overview of the dimensions used to evaluate the symbols, their relevance to 
symbols' evaluation, and the relationships between them that have been reported in the literature.

\section{Dimensions of interest}

Familiarity The familiarity of a symbol refers to the frequency with which it is encountered (McDougall et al., 1999). Familiarity seems to be highly relevant for the accurate understanding of a symbol. Not only does familiarity improve comprehension (e.g., Cahill, 1975), it also affects the usability of symbols, as has been shown by the considerable increase in users' performance after learning symbol-function relationships (e.g., Montagne, 2013). Additionally, it has been shown that familiarity and experience with a symbol reduces the impacts that other variables (e.g., concreteness level or the use of color) have on its comprehension (e.g., Christ \& Corso, 1982; Isherwood, McDougall, \& Curry, 2007; Stammers, George, \& Carey, 1989). Thus, familiarity appears to be a key attribute for understanding symbols.

As was noted by McDougall and colleagues (1999), having access to objective frequencies of occurrence of symbols is a rather difficult task, especially when symbols are compared to words, for which indexes of frequency of occurrence in many languages are available (e.g., the Brown corpus for EnglishKučera \& Francis, 1967; and the CELEX corpus for DutchDutch Center for Lexical Information, 1995). For these reasons, subjective measures are more common, such as subjective estimations of the frequency with which participants encounter a given symbol (e.g., McDougall et al., 1999). Hence, we asked our participants to indicate how frequently they encounter or see the stimulus in their daily routine. More frequently encountered stimuli should be considered more famil$\operatorname{iar}(1=$ Not familiar, 7 = Very familiar $)$.

Visual complexity The complexity of a pictorial stimulus refers to the degree of detail or intricacy of the symbol (e.g., McDougall et al., 1999; Snodgrass \& Vanderwart, 1980). Some authors choose to use the opposite term - simplicity to refer to the same concept (e.g., Chan \& Chan, 2013; Ng \& Chan, 2007). Due to its influence on the way that a stimulus is processed and evaluated, complexity is one of the most frequently measured characteristics by researchers providing normative data for visual stimuli (e.g., Alario \& Ferrand, 1999; Bonin, Peereman, Malardier, Méot, \& Chalard, 2003; McDougall et al., 1999; Snodgrass \& Vanderwart, 1980). Research suggests that complexity determines the ease with which a stimulus is processed (Alario \& Ferrand, 1999). For example, more complex images take longer time to categorize than simpler ones (e.g., Snodgrass \& Vanderwart, 1980). Stimulus complexity has also been shown to have a negative influence on performance speed in visual search tasks (Byrne, 1993; McDougall, de Bruijn, \& Curry, 2000; McDougall et al., 2006; Reppa, Playfoot, \& McDougall, 2008). However, despite the important role of visual complexity in the visual search for symbols, complexity does not seem to be directly involved in symbol identification (McDougall et al., 2000; see also Biederman, 1987; Paivio, Clark, Digdon, \& Bons, 1989; Snodgrass \& Corwin, 1988; Snodgrass \& Yuditsky, 1996). Recently, Gerlach and Marques (2014) showed that the impact of visual complexity on visual object processing depends on the task requirements: When difficult decisions regarding an object are required (e.g., decisions that require a great deal of differentiation between objects), complexity seems to hinder performance, whereas it facilitates performance for easy decisions (e.g., those that require little differentiation between objects).

The literature suggests the existence of a negative correlation between visual complexity and familiarity (see Forsythe, Mulhern, \& Sawey, 2008). For example, Snodgrass and Vanderwart (1980) showed that visually complex pictures were rated as being less familiar (see also Alario \& Ferrand, 1999; Bonin et al., 2003; McDougall et al., 1999), although the correlation between the two variables was only small to moderate. Alario and Ferrand argued that this negative association emerges because visually complex pictures tend to be perceived as novel stimuli (for a discussion on the possible confound between familiarity and complexity measures, see Forsythe et al., 2008). Also, alluding to the association between the two dimensions, the beneficial impact of familiarity on visual search tasks does not seem to be observed in the case of complex stimuli (McDougall et al., 1999; 2006).

Despite the proposed objective metrics to define the visual complexity of pictorial stimuli (e.g., the size of the digitalized stimulus picture files, as in the International Picture Naming Project—Székely \& Bates, 2000; or the number of lines, letters, or simple shapes that an icon contains - Garcia, Badre, \& Stasko, 1994; for a review, see Forsythe et al., 2008), visual complexity is often measured in subjective terms. In this case, the instructions must emphasize that participants should indicate the complexity level of the visual characteristics of the symbols and not the complexity level of the object or concept they depict (e.g., Alario \& Ferrand, 1999; Bonin et al., 2003; Isherwood et al., 2007; McDougall et al., 1999; Sanfeliu \& Fernandez, 1996; Snodgrass \& Vanderwart, 1980). We used this type of instructions and asked participants to indicate how much visual detail and complexity the stimulus contain. The more details it contains, the more complex the image should be considered $(1=$ Very simple, $7=$ Very complex $)$.

Concreteness According to McDougall and colleagues' (1999) definition, the concreteness of a symbol refers to the extent to which it depicts real objects, materials, or people. Thus, concrete symbols depict "objects, places, and people that we are already familiar with in the real world" (p. 488), whereas abstract symbols have a less obvious link to the real 
objects, and thus "represent information using graphic features such as shapes, arrows, and so on" (p. 488). Concreteness is considered one of the most relevant properties of symbols and icons (see Isherwood et al., 2007; Moyes \& Jordan, 1993). When stimuli depict objects with which individuals are familiar with, people can rely on their knowledge to interpret their meaning. However, if on the one hand some studies have shown that people respond faster and more accurately to concrete symbols (e.g., Arend, Muthig, \& Wandmacher, 1987; Rogers \& Oborne, 1987; Stammers \& Hoffman, 1991; Stotts, 1998), others have suggested that these performance advantages are not permanent and decrease as a function of individuals' experience with the symbols (e.g., Green \& Barnard, 1990; McDougall et al., 2000).

Concreteness is often associated with the use of extra detail in the symbols, in order to depict objects in an obvious manner and in close connection with real-world items. In other words, concrete symbols are more complex due to the extra detail they include. Garcia and collaborators (1994) provided support for this hypothesis by showing that concrete symbols fared better in their objective visual complexity measure (see the Visual Complexity section above for details). Thus, concrete symbols seem to be associated with higher complexity, and abstract symbols with higher simplicity. However, McDougall and colleagues (1999) did not find a significant correlation between concreteness and complexity, suggesting that concrete symbols may also be simple, and abstract symbols may be complex. In our study, we asked participants to indicate how concrete the symbol is. Stimuli depicting objects, materials, or people should be considered concrete, and otherwise the symbol should be considered more abstract $(1=$ Totally abstract, 7 = Totally concrete).

Aesthetic appeal This dimension refers to how much a symbol is liked by individuals (e.g., McDougall \& Reppa, 2008). This characteristic seems to be particularly important, for example, for symbol usability and users' performance with computer interfaces, since it determines the amount of effort that individuals are willing to make in order to learn how to use an interface (see Reppa et al., 2008). Aesthetic appeal is also related to other symbol dimensions, the most significant being familiarity and visual complexity, where familiar and visually simple symbols are liked more than unfamiliar and complex symbols (see McDougall \& Reppa, 2008). The relation between aesthetic appeal and visual complexity can also be observed in visual search tasks. In these tasks, aesthetic appeal facilitates performance when stimuli are complex, but does not have any impact when stimuli are visually simple (Reppa et al., 2008). Following McDougall and Reppa (2008), we asked participants to indicate how visually appealing the symbol is, considering its visual characteristics and not the object or concept that it may depict ( 1 = Visually unpleasant/unappealing, 7 = Visually very pleasant/appealing).
Valence Valence can be defined as the intrinsic attractiveness or aversiveness of a stimulus (e.g., Frijda, 1986). It is the dimension that captures the positive-negative nature of an object, an event, or a situation. In the psychology literature, the term is also applied to characterize and categorize specific emotions (e.g., fear and anger are negatively valenced, whereas joy and happiness are positively valenced) or behaviors (e.g., positive valence refers to approach behaviors, and negative valence refers to avoidance/withdrawal behaviors; for a review of the uses of the term "valence" since it was introduced in the literature, see Colombetti, 2005).

Valence has a well-documented impact on the way that people process and judge stimuli. For example, Angrilli, Cherubini, Pavese, and Manfredini (1997) showed that participants judge negatively valenced images as being presented for shorter durations than positive images. In the domain of memory, Adelman and Estes (2013) showed that in a recognition test of words, individuals' performance improved when the stimuli became more extreme in either positivity or negativity.

However, valence has not been thoroughly explored in the domain of normative ratings for symbols. This may be due to the fact that when aesthetic appeal is assessed (see the Aesthetic Appeal section above), that dimension already captures part of the positive-negative nature of the stimuli. However, since symbols may vary in the meanings they convey, it is also relevant to evaluate the valence associated with that meaning, as has been the case for words (e.g., Bradley \& Lang, 1999a; Moors et al., 2013; Söderholm, Häyry, Laine, \& Karrasch, 2013; Warriner, Kuperman, \& Brysbaert, 2013). Like aesthetic appeal, valence is highly associated with familiarity. Not only do familiar stimuli seem to be associated with positive feelings and preferred over new ones (the "mere-exposure effect"; Zajonc, 1968), but individuals also tend to judge positive stimuli as being more familiar than negative ones (e.g., Garcia-Marques, Mackie, Claypool, \& GarciaMarques, 2004; Monin, 2003). Additionally, studies that use physiological measures (e.g., facial muscle activity) have shown that the exposure to repeated pictures is associated with a higher activation of the smiling muscle (zygomaticus major; e.g., Harmon-Jones \& Allen, 2001), whereas the contraction of that same muscle leads to stimuli being judged as familiar (e.g., Phaf \& Rotteveel, 2005).

In the present study, we asked participants to indicate the extent to which they considered each symbol to refer to something positive/pleasant or something negative/unpleasant $(1=$ Refers to something very negative/unpleasant, $7=$ Refers to something very positive/pleasant).

Arousal Along with valence, arousal appears to be one of the fundamental dimensions of affect, differentiating states of high activation/excitement from more relaxed/calm emotional states (Osgood, Suci, \& Tannenbaum, 1957). Like valence, arousal has rarely been assessed in the available normative 
ratings for symbols. However, this dimension is frequently measured in other types of stimuli, such as words (e.g., ANEW; Bradley \& Lang, 1999a; Moors et al., 2013; Warriner et al., 2013), sounds (IADS; Bradley \& Lang, 1999b; Redondo, Fraga, Padrón, \& Piñeiro, 2008), and also real-life pictures of diverse contents (IAPS; Lang et al., 2008; see also Grühn \& Scheibe, 2008).

Most studies that have measured the arousal elicited by pictorial stimuli (i.e., IAPS images) have shown that the association between valence and arousal follows a U-shaped function. That is, stimuli that are more extreme in positive or negative valence are also rated as being more arousing (Backs, da Silva, \& Han, 2005; Ito, Cacioppo, \& Lang, 1998; Lang, Bradley, \& Cuthbert, 1998; Libkuman, Otani, Kern, Viger, \& Novak, 2007; but for exceptions, see Grühn \& Scheibe, 2008, and Ribeiro, Pompéia, \& Bueno, 2005). In the present study, we asked participants to evaluate the extent to which the symbol refers to something arousing/exciting or passive/calm $(1=$ Refers to something very passive/calm, $7=$ Refers to something very arousing/exciting).

Meaningfulness In their early study providing normative ratings of symbol characteristics, McDougall and collaborators (1999) asked participants to indicate the extent to which a symbol conveyed meaning (in a continuum ranging from totally meaningless to totally meaningful). As in previous studies (see Rogers, 1989; Rogers \& Oborne, 1987), meaningfulness was highly correlated with concreteness. The authors suggested that the association between these two symbol dimensions rests on the fact that concrete symbols depict familiar and well-known objects - thus, their meaning can be extracted directly from the obvious representation of real-world items. In fact, the three dimensions were all highly correlated, so that concrete symbols were also evaluated as being familiar, and the most familiar symbols were also the most meaningful. In this study, we asked participants to indicate the extent to which the symbol conveys a meaning $(1=$ It has no meaning at all, 7 = It has a lot of meaning).

The brief literature review presented on the most commonly used dimensions to evaluate and classify symbols suggests the relevant role they play in the selection of stimuli to examine psychological phenomena. In the following sections, we present subjective norms for each of these dimensions for a new and comprehensive set of symbols, the correlations between them, as well as a descriptive analysis of each symbol's meaning.

\section{Method}

\section{Participants}

A sample of 388 Portuguese respondents ( $72.4 \%$ female; $M_{\text {age }}=$ $28.90, S D=11.23$ ) volunteered to participate in a Web survey.
The sample comprised mostly students (49.5\%) and active workers $(35.1 \%)$, with at least a high school education degree.

\section{Development of the stimulus set}

To create the stimulus set, free icon-based fonts were downloaded from the website www.1001fonts.com (license agreements were checked, and all fonts are free for commercial use). In these fonts, each character (letters, numbers, punctuation, etc.) corresponds to a symbol (see Fig. 1). Each symbol was generated in black on a white background and saved as a single image file $(250 \times 250$ pixels, 72 dpi, grayscale, JPG format). The stimulus set ( $N=$ 600) comprises symbols depicting various contents: for example, social media and technology (e.g., the Modern Pictograms font), transportation (e.g., the Glyphyx One font) , and leisure activities (e.g., the Glyphyx Two font). The set also comprises nonfigurative stimuli (e.g., the SF Distant Galaxy Symbols font). Symbols containing written information (e.g., the word "Danger") were not included in the set. The full stimulus set (and corresponding database in Excel format, organized by symbol code and by each of the evaluated dimensions) is provided as supplementary material and can also be obtained upon request to the first author. This set is also available in higher resolution $(500 \times 500$ pixels $)$.

\section{Procedure and measures}

The study was conducted using the Qualtrics software. Participants were invited (e.g., via institutional e-mail and social networking websites) to collaborate on a Web survey about the perception and evaluation of visual stimuli. By clicking on a hyperlink, participants were directed to a secure webpage that again informed them about the goals of the study and its expected duration (approximately $25 \mathrm{~min}$ ). Participants were also informed that all of the data collected would be treated anonymously and that they could abandon the study at any point by simply closing the browser (for best practices in conducting Web surveys, see Barchard \& Williams, 2008). After consenting to collaborate in the study (by checking the "I agree" option), participants were asked to provide information regarding their age, sex, educational level, and current occupation.

Instructions were provided simultaneously for all symbol dimensions. Participants were asked to evaluate each stimulus regarding its aesthetic appeal, familiarity (subjective frequency), visual complexity, concreteness, valence, arousal, and meaningfulness (for the detailed instructions, see Table 1). The symbol dimensions were always presented in this order. The instructions highlighted that responses should be fast and spontaneous and that there were no right or wrong answers.

After evaluating how meaningful a symbol was, participants were asked to succinctly describe the first meaning that came to their mind, or to select the option "I do not know" if 
Font

\begin{tabular}{|c|c|c|c|c|c|}
\hline \multicolumn{6}{|l|}{ GlyphxOneNF } \\
\hline character/symbol code & $\mathrm{P} / \mathrm{S} 015$ & U / S019 & $\mathrm{k} / \mathrm{S} 033$ &.$/ \mathrm{S} 061$ & \#/S068 \\
\hline \multicolumn{6}{|l|}{ GlyphxTwoNF } \\
\hline character/symbol code & F/S084 & $\mathrm{U} / \mathrm{S} 097$ & $\mathrm{Z} / \mathrm{S} 102$ & s/S119 & $\mathrm{x} / \mathrm{S} 122$ \\
\hline \multicolumn{6}{|l|}{ MaritimeFlags } \\
\hline character / symbol code & A / S343 & d / S346 & $1 / S 354$ & $0 / \mathrm{S} 370$ & $\% /$ S369 \\
\hline \multicolumn{6}{|l|}{ ModernPictograms } \\
\hline character/symbol code & $\mathrm{A} / \mathrm{S} 207$ & $\mathrm{G} / \mathrm{S} 212$ & $\mathrm{O} / \mathrm{S} 220$ & $\mathrm{P} / \mathrm{S} 221$ & w/S246 \\
\hline \multicolumn{6}{|c|}{ SFDistantGalaxySymbols } \\
\hline character / symbol code & $\mathrm{K} / \mathrm{S} 303$ & $\mathrm{P} / \mathrm{S} 306$ & $\mathrm{~b} / \mathrm{S} 314$ & f/S318 & $\mathrm{n} / \mathrm{S} 325$ \\
\hline
\end{tabular}

Fig. 1 Examples of symbols included in the stimulus set, along with the icon font information and indications of the corresponding character and symbol codes

they were not able to provide a specific meaning. Before initiating their evaluations, participants were presented with a practice trial to guarantee that they understood the instructions and all of the evaluation scales. The stimulus used in the practice trial was not included in the final set. Then, participants proceeded to the main task. In order to prevent fatigue and demotivation, the software was programed to select a random subset of 50 symbols from the total pool of 600 stimuli for each participant. Each symbol was presented in a single page of the online questionnaire, with the symbol at the top left corner of the page and all of the rating scales below. The presentation order of the stimuli was randomized for each participant. Upon completing the task, the participants were thanked and debriefed.

\section{Results}

The full set of symbols and the norms for aesthetic appeal, familiarity, visual complexity, concreteness, valence, arousal,

Table 1 Instructions and scale anchors for each dimension

\begin{tabular}{|c|c|c|}
\hline Dimension & Instructions & Scale \\
\hline $\begin{array}{l}\text { 1. Aesthetic appeal (e.g., } \\
\text { McDougall \& Reppa, 2008) }\end{array}$ & $\begin{array}{l}\text { In your opinion, considering the visual characteristics of the } \\
\text { symbol (and not the object or concept it may depict), how } \\
\text { visually appealing is the symbol? }\end{array}$ & $\begin{array}{l}1=\text { Visually unpleasant/unappealing } \\
7=\text { Visually very pleasant/appealing }\end{array}$ \\
\hline $\begin{array}{l}\text { 2. Familiarity (e.g., McDougall } \\
\text { et al., 1999) }\end{array}$ & $\begin{array}{l}\text { How frequently do you encounter or see this stimulus in your } \\
\text { daily routine? More frequently encountered stimuli are } \\
\text { more familiar. }\end{array}$ & $\begin{array}{l}1=\text { Not familiar } \\
7=\text { Very Familiar }\end{array}$ \\
\hline $\begin{array}{l}\text { 3. Visual complexity } \\
\text { (e.g., McDougall et al., } \\
\text { 1999; Snodgrass \& } \\
\text { Vanderwart, 1980) }\end{array}$ & $\begin{array}{l}\text { Considering the complexity of the visual characteristics of the } \\
\text { stimulus, and not those of the object or concept that can be } \\
\text { related to the symbol, how much visual detail and complexity } \\
\text { does this stimulus contain? The more details the symbol } \\
\text { contains, the more complex it is. }\end{array}$ & $\begin{array}{l}1=\text { Very simple } \\
7=\text { Very complex }\end{array}$ \\
\hline $\begin{array}{l}\text { 4. Concreteness (e.g., } \\
\text { McDougall et al., 1999) }\end{array}$ & $\begin{array}{l}\text { How concrete is this stimulus? Stimuli that, in your opinion, } \\
\text { refer to objects, materials or people should be considered } \\
\text { concrete. Otherwise, they should be considered as more abstract. }\end{array}$ & $\begin{array}{l}1=\text { Totally abstract } \\
7=\text { Totally concrete }\end{array}$ \\
\hline 5. Valence (Moors et al., 2013) & $\begin{array}{l}\text { To what extent do you consider this stimulus refers to } \\
\text { something positive/pleasant or negative/unpleasant. }\end{array}$ & $\begin{array}{l}1=\text { Refers to something very negative/unpleasant, } \\
7=\text { Refers to something very positive/pleasant }\end{array}$ \\
\hline 6. Arousal (Moors et al., 2013) & $\begin{array}{l}\text { To what extent do you consider this stimulus refers to something } \\
\text { arousing/exciting or passive/calm? }\end{array}$ & $\begin{array}{l}1=\text { Refers to something very passive/calm, } \\
7=\text { Refers to something very arousing/exciting }\end{array}$ \\
\hline $\begin{array}{l}\text { 7. Meaningfulness (e.g., } \\
\text { McDougall et al., 1999) }\end{array}$ & Please indicate to what extent this stimulus conveys a meaning. & $\begin{array}{l}1=\text { It has no meaning at all, } \\
7=\text { It has a lot of meaning }\end{array}$ \\
\hline
\end{tabular}


and meaningfulness can be downloaded as a supplemental archive with this article.

In the following sections, we first present the preliminary analysis regarding outliers, gender differences, and reliability. We then examine the subjective rating norms for each dimension and present the frequency distribution of symbols across the dimensions levels (i.e., low, moderate, and high). Subsequently, we present the associations between dimensions. Finally, we present the symbols' meaning analysis and the frequency distribution of meaning levels across dimensions.

\section{Preliminary analysis}

Only fully complete surveys were included in the data analysis. Thus, there were no missing cases. Outliers were determined based on the criterion of 2.5 standard deviations above or below the mean evaluation of each stimulus in a given dimension. The result of this analysis yielded a low percentage $(1.33 \%)$ of outlier ratings. We also found no indication of participants responding systematically in the same way - that is, always using the same value of the scale. Therefore, no responses were excluded.

In order to test for gender differences in the ways that participants rated the symbols, the mean evaluations on each dimension were compared between male and female participants. No gender differences were found (see Table 2).

To test the response consistency of participants' ratings in each dimension, we compared two subsamples of equal size ( $n$ $=194$ ) randomly selected from the main sample. No differences between the subsamples emerged, all $t \mathrm{~s}<1$. These analyses were repeated for males $\left(n_{1}=50, n_{2}=57\right)$ and females $\left(n_{1}=\right.$ $144, n_{2}=137$ ) separately. Again, no significant differences were found, all $t \mathrm{~s}<1$. Therefore, all of the subsequent analyses were performed using the total sample. Moreover, ratings across the seven quantitative dimensions were reliable for the whole sample and for the subsamples of males and females (Cronbach's alpha $=.78, .82$, and .77 , respectively; Spearman-Brown splithalf reliability $=.86, .89$, and .84 , respectively).

\section{Subjective rating norms}

In order to define subjective rating norms, the data was coded and analyzed by symbol. The number of participants evaluating each symbol varied between 30 and 39. The frequencies, means, standard deviations, and confidence intervals on each dimension were calculated for each symbol and are presented in Appendix 1. On the basis of these results, we categorized the symbols as being low, moderate, or high in each dimension. Specifically, when the confidence intervals included the response scale midpoint (i.e., 4) symbols were considered to be "moderate" in a given dimension. Symbols with the upper bound of their confidence interval below the scale midpoint were considered to be "low" in a given dimension. And symbols with the lower bound of their confidence interval above the scale midpoint were considered to be "high" in a given dimension. See, for instance, symbol S001's evaluation on aesthetic appeal $(M=2.92, S D=1.77,95 \%$ CI $[2.33,3.51])$. Because the upper bound was below the scale midpoint, this symbol was categorized as being low in this dimension.

The frequencies observed for each level (low, moderate, and high) of the dimensions are presented in Table 3.

Most symbols were evaluated as being moderately or highly appealing ( $n \mathrm{~s}=268$ and 211, respectively), highly familiar ( $n=$ $303)$, simple $(n=347)$, highly concrete $(n=346)$, neutral or positive ( $n$ s $=238$ and 264 , respectively), moderately arousing $(n=339)$, and highly meaningful $(n=353)$. Examples of symbols for each level in each dimension are presented in Fig. 2.

As is shown in Table 3, the intersection of the levels across dimensions shows, for instance, that none of the symbols was simultaneously evaluated as both negative and highly appealing, highly complex and highly familiar, very abstract and highly familiar, meaningless and highly familiar or highly concrete, or meaningful and very abstract. On the contrary, large subsets of symbols were evaluated as being simultaneously highly familiar and very concrete $(n=283)$, positive $(n=206)$, or meaningful $(n=293)$; more simple and more meaningful $(n=210)$; positive and very concrete $(n=221)$ or meaningful $(n=231)$; or more concrete and more meaningful $(n=331)$.

Table 2 Evaluations (means and standard deviations) in each dimension for the total sample and for males and females, along with mean difference test results

\begin{tabular}{|c|c|c|c|c|c|c|c|c|}
\hline \multirow[b]{2}{*}{ Dimension } & \multicolumn{2}{|c|}{ Total Sample $(N=388)$} & \multicolumn{2}{|c|}{ Males $(n=17)$} & \multicolumn{2}{|c|}{ Females $(n=281)$} & \multicolumn{2}{|c|}{ Difference Test } \\
\hline & $M$ & $S D$ & $M$ & $S D$ & $M$ & $S D$ & $t(386)$ & $p$ \\
\hline Aesthetic appeal & 4.18 & 0.67 & 4.21 & 0.63 & 4.17 & 0.69 & 0.46 & .644 \\
\hline Familiarity & 4.45 & 0.76 & 4.44 & 0.74 & 4.46 & 0.76 & -0.14 & .887 \\
\hline Visual complexity & 3.26 & 0.85 & 3.36 & 0.81 & 3.22 & 0.86 & 1.49 & .138 \\
\hline Concreteness & 4.64 & 0.65 & 4.59 & 0.63 & 4.65 & 0.66 & -0.90 & .371 \\
\hline Valence & 4.34 & 0.42 & 4.29 & 0.40 & 4.36 & 0.43 & -1.40 & .162 \\
\hline Arousal & 4.34 & 0.48 & 4.33 & 0.44 & 4.34 & 0.49 & -0.24 & .807 \\
\hline Meaningfulness & 4.62 & 0.67 & 4.61 & 0.63 & 4.62 & 0.68 & -0.11 & .911 \\
\hline
\end{tabular}


Table 3 Symbols' frequency distributions across dimension levels

\begin{tabular}{|c|c|c|c|c|c|c|c|c|c|c|c|c|c|c|c|c|c|c|c|}
\hline & \multicolumn{3}{|c|}{ Familiarity } & \multicolumn{3}{|c|}{ Visual complexity } & \multicolumn{3}{|c|}{ Concreteness } & \multicolumn{3}{|c|}{ Valence } & \multicolumn{3}{|c|}{ Arousal } & \multicolumn{3}{|c|}{ Meaningfulness } & \multirow[t]{2}{*}{ Total } \\
\hline & $\mathrm{L}$ & M & $\mathrm{H}$ & $\mathrm{L}$ & M & $\mathrm{H}$ & $\mathrm{L}$ & M & $\mathrm{H}$ & $\mathrm{L}$ & M & $\mathrm{H}$ & $\mathrm{L}$ & M & $\mathrm{H}$ & $\mathrm{L}$ & M & $\mathrm{H}$ & \\
\hline \multicolumn{20}{|c|}{ Aesthetic Appeal } \\
\hline Low & 91 & 20 & 10 & 68 & 42 & 11 & 76 & 29 & 16 & 55 & 65 & 1 & 24 & 78 & 19 & 75 & 30 & 16 & 121 \\
\hline Moderate & 53 & 104 & 111 & 160 & 94 & 14 & 53 & 75 & 140 & 43 & 152 & 73 & 17 & 181 & 70 & 46 & 80 & 142 & 268 \\
\hline High & 9 & 20 & 182 & 119 & 85 & 7 & 8 & 13 & 190 & 0 & 21 & 190 & 4 & 80 & 127 & 5 & 11 & 195 & 211 \\
\hline \multicolumn{20}{|l|}{ Familiarity } \\
\hline Low & & & & 75 & 51 & 27 & 124 & 25 & 4 & 39 & 101 & 13 & 26 & 113 & 14 & 122 & 29 & 2 & 153 \\
\hline Moderate & & & & 73 & 66 & 5 & 13 & 72 & 59 & 21 & 78 & 45 & 11 & 91 & 42 & 4 & 82 & 58 & 144 \\
\hline High & & & & 199 & 104 & 0 & 0 & 20 & 283 & 38 & 59 & 206 & 8 & 135 & 160 & 0 & 10 & 293 & 303 \\
\hline \multicolumn{20}{|c|}{ Visual Complexity } \\
\hline Low & & & & & & & 75 & 73 & 199 & 47 & 141 & 159 & 37 & 199 & 111 & 67 & 70 & 210 & 347 \\
\hline Moderate & & & & & & & 39 & 39 & 143 & 41 & 80 & 100 & 7 & 118 & 96 & 39 & 42 & 140 & 221 \\
\hline High & & & & & & & 23 & 5 & 4 & 10 & 17 & 5 & 1 & 22 & 9 & 20 & 9 & 3 & 32 \\
\hline \multicolumn{20}{|l|}{ Concreteness } \\
\hline Low & & & & & & & & & & 30 & 96 & 11 & 24 & 104 & 9 & 117 & 20 & 0 & 137 \\
\hline Moderate & & & & & & & & & & 17 & 68 & 32 & 10 & 88 & 19 & 9 & 86 & 22 & 117 \\
\hline High & & & & & & & & & & 51 & 74 & 221 & 11 & 147 & 188 & 0 & 15 & 331 & 346 \\
\hline \multicolumn{20}{|l|}{ Valence } \\
\hline Low & & & & & & & & & & & & & 15 & 42 & 41 & 28 & 20 & 50 & 98 \\
\hline Moderate & & & & & & & & & & & & & 20 & 183 & 35 & 90 & 76 & 72 & 238 \\
\hline High & & & & & & & & & & & & & 10 & 114 & 140 & 8 & 25 & 231 & 264 \\
\hline \multicolumn{20}{|l|}{ Arousal } \\
\hline Low & & & & & & & & & & & & & & & & 25 & 9 & 11 & 45 \\
\hline Moderate & & & & & & & & & & & & & & & & 95 & 88 & 156 & 339 \\
\hline High & & & & & & & & & & & & & & & & 6 & 24 & 186 & 216 \\
\hline Total & & & & & & & & & & & & & & & & 126 & 121 & 353 & \\
\hline
\end{tabular}

$N=600$ symbols. Levels across dimensions: $\mathrm{L}=$ low, $\mathrm{M}=$ moderate, $\mathrm{H}=$ high

\section{Associations between dimensions}

The associations between dimensions were also explored. The overall results show positive and strong correlations (see Table 4). Specifically, and in line with the literature, we observed a strong positive correlation between familiarity and several other dimensions, including aesthetic appeal $(r=.470$, $d=1.06)$, concreteness $(r=.709, d=2.01)$, valence $(r=.355, d$ $=0.76)$, and meaningfulness $(r=.753, d=2.29)$. Also as expected, familiarity was negatively correlated with visual complexity $(r=-.061, d=0.12)$. The small effect size of this association parallels past evidence described in the literature (e.g., Bonin et al., 2003; McDougall et al., 1999; for a review, see Forsythe et al., 2008). Furthermore, congruent with the findings reported by McDougall and colleagues (1999; see also Rogers, 1989; Rogers \& Oborne, 1987) concreteness was positively correlated with meaningfulness $(r=.727, d=2.12)$. The analysis also revealed two further associations of interest. First, we found a positive correlation between visual complexity and aesthetic appeal $(r=.103, d=0.21)$, which diverges from McDougall and Reppa's (2008) results. Second, we found a negative correlation between visual complexity and concreteness ( $r=-.042, d=0.08$ ), which differs from the absence of a correlation between these dimensions reported by McDougall and Reppa. In both cases, the effect sizes of these correlations were very small, and thus should be interpreted with caution.

\section{Analysis of symbols' meaning}

Besides asking participants how meaningful the symbols were, we also asked them to provide the actual meaning that they thought the symbol had. We computed the proportions of valid responses, considering the sample size that evaluated a given stimulus. Responses such as "I cannot name it" or idiosyncratic descriptions (e.g., "The father of my friend John") were not included in these analyses ( $0.42 \%$ of responses). The mean number of valid responses per symbol varied from 0 to $38(M=21, S D=8.75)$. Two independent judges coded the meaning provided by the participants for each symbol and categorized them in a broader theme (for a similar strategy, 


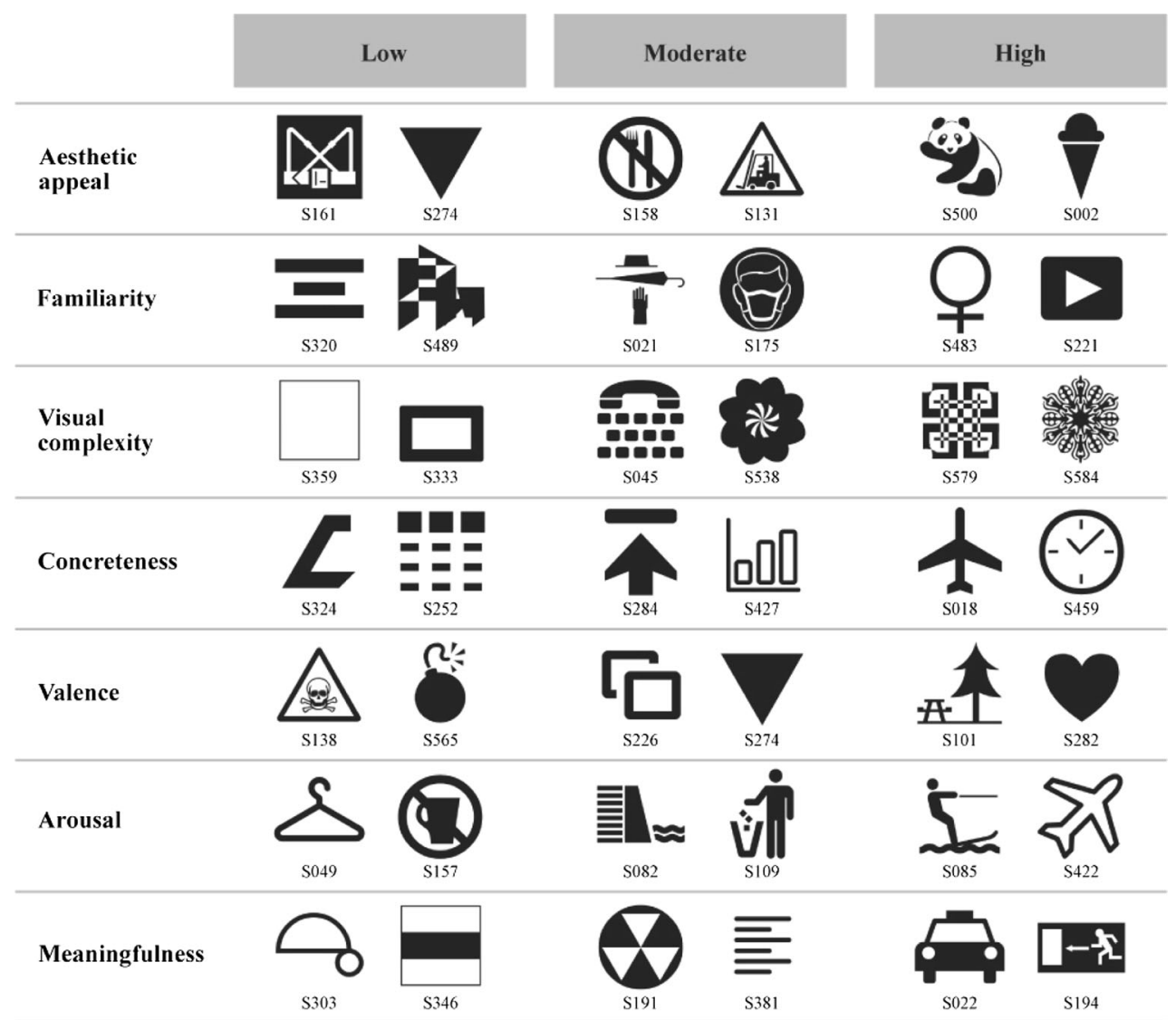

Fig. 2 Sample symbols in each level across dimensions (symbol codes are included)

see, e.g., Massey, 2010; Soares et al., 2012). Interjudge agreement was obtained for $96 \%$ of the meanings provided. The 500 meanings that failed to gain prior consensus were resolved by agreement between the two judges.

Synonyms (e.g., "iPhone" and "smartphone," S220), singular/plural forms (e.g., "car" and "cars," S432), and exemplars of the same category (e.g., "boat" and "ship," S493) were included in the same category. Semantically related concepts referring to different actions (e.g., "airplane"' and "airplane takeoff," S016), different objects or agents (e.g., "babies" and "baby stroller," S041), or specificities inherent to a symbol (e.g., "turn left" and "directions," S286) were coded as distinct categories. The meanings of 55 symbols were not categorized due to a low frequency of valid responses $(M=5.09)$, high heterogeneity of the descriptions (e.g., S576 was only described as "shapes," "Rorschach test, " or "metamorphosis"), and/or a lack of consensus between the judges. Also, the sum of the percentages of categories does not necessarily equal $100 \%$, due to heterogeneity of the meanings provided. For example, symbol S006 was described by $70.4 \%$ of participants as "mail" and by $14.8 \%$ of participants as "post office"; the remaining responses $(n=4)$ were diverse and unrelated to any of these categories. The complete content analysis can be found in Appendix 2.

Table 4 Pearson's correlations (and effect sizes, Cohen's $d$ ) between the dimensions

\begin{tabular}{|c|c|c|c|c|c|c|}
\hline Dimensions & 1 & 2 & 3 & 4 & 5 & 6 \\
\hline 1. Aesthetic appeal & - & & & & & \\
\hline 2. Familiarity & $.470^{* * * *}(d=1.06)$ & - & & & & \\
\hline 3. Visual complexity & $.103^{* * * *}(d=0.21)$ & $-.061^{* * *}(d=0.12)$ & - & & & \\
\hline 4. Concreteness & $.424^{* * * *}(d=0.94)$ & $.709^{* * * *}(d=2.01)$ & $-.042^{* * * *}(d=0.08)$ & - & & \\
\hline 5. Valence & $.567^{* * * *}(d=1.38)$ & $.355^{* * * *}(d=0.76)$ & $.043^{* * *}(d=0.07)$ & $.341^{* * * *}(d=0.73)$ & - & \\
\hline 6. Arousal & $.322^{* * * *}(d=0.68)$ & $.287^{* * * *}(d=0.60)$ & $.178^{* * * *}(d=0.36)$ & $.312^{* * *}(d=0.66)$ & $.314^{* * * *}(d=0.66)$ & - \\
\hline 7. Meaningfulness & $.461^{* * * *}(d=1.04)$ & $.753^{* * * *}(d=2.29)$ & $-.012(d=0.02)$ & $.727^{* * * *}(d=2.12)$ & $.357^{* * * *}(d=0.76)$ & $.366^{* * *}(d=0.79)$ \\
\hline
\end{tabular}

**** Correlation is significant at the .001 level (two-tailed). 
We computed the proportion of valid responses for each symbol (number of valid meaning responses for a given symbol / number of participants evaluating that symbol). On the basis of that proportion, we classified each symbol as having a low $(\mathrm{Q} 1$, proportion $\leq .45)$, a moderate $(\mathrm{Q} 2$ and Q3, .45 < proportion $<.88)$, or a high $(\mathrm{Q} 4$, proportion $\geq .88)$ subjective meaningfulness. In terms of the intersections of these indicators with the indicators of the three levels in each dimension, we observed that none of the symbols with low subjective meaning (i.e., those with a lower number of valid responses) was categorized as being highly familiar, concrete, or meaningful. Not surprisingly, none of the symbols with high subjective meaning (i.e., those with a higher number of valid responses) was categorized as being unfamiliar, highly complex, abstract, or meaningless (see Table 5 for the full results).

\section{Discussion}

The aim of this study was to develop a normative database of symbols that can be used as a research tool in different psychological research domains. In comparison with other type of stimuli (e.g., words or even real-life pictures), validated norms of symbol sets are scarce. The exception is McDougall and colleagues' (1999) data set of 239 symbols. We present a new and larger set (600 new symbols) - the $L S D$ - that includes more contemporary symbols in terms of both content and design. Furthermore, we tested each symbol in several dimensionsnamely, aesthetic appeal, familiarity, visual complexity, concreteness, valence, arousal, and meaningfulness. The provision of valence and arousal ratings constitutes an important addition to the mainstream measures in the field, offering researchers objective evaluative indicators in these dimensions. Additionally, we analyzed the meanings that participants ascribed to each symbol, uncovering their most common interpretations.

LSD includes an extensive and diverse set of symbols, and descriptive analysis showed that the symbols vary in the evaluated dimensions. This variety allows for disentangling the effects of different dimensions. For example, in the memory research domain, advantages in recognition and recall have been observed for both extreme valence (e.g., Adelman \&
Estes, 2013) and valence and arousal (Bradley, Greenwald, Petry, \& Lang, 1992). Thus, the variation in ratings across dimensions constitutes an advantage for the selection of stimuli in one or several dimensions of interest, while controlling for others.

The overall pattern of correlations between the dimensions is in line with the literature. Namely, we observed strong positive correlations between familiarity and several other dimensions (e.g., aesthetic appeal, concreteness, valence, and meaningfulness), as well as a positive correlation between concreteness and meaningfulness. Additionally, our meaning analysis results showed that symbols with a lower number of valid responses (i.e., less subjective meaning ascribed) were the least familiar, concrete, or meaningful, whereas symbols with a higher number of valid responses (i.e., more subjective meaning ascribed) were less complex and more familiar, concrete, and meaningful. These results also indicate that our set varies in terms of its depicted contents (e.g., animals, objects, people, geometric shapes, patterns, etc.). The diversity of contents represented in our symbol set permits the selection of stimuli for priming specific concepts (see Bargh \& Chartrand, 2000). For instance, the cross (S595) or the star of David (S570) symbols may be used for activating spirituality or religion-related concepts (e.g., Johnson et al., 2014).

Altogether, these findings provide robustness to our database and offer several possibilities in what concerns the selection of symbols based on the required level on each dimension, as well as their combinations. Yet the cultural specificity of symbol interpretations must be acknowledged, along with the need for cross-validation. Few symbols are universally understood, and usually some learning of the correct interpretation is required (Tijus et al., 2007). Moreover, the interpretation of a particular symbol may not be independent of the context (see, e.g., Cahill, 1975; Wolff \& Wogalter, 1998). For example, the symbol of a key (S511) in a shopping mall could indicate the location of a key-duplicating store, whereas in a computer it may indicate the need for a password. This sensitivity to contextual influences may constitute a problem from the communication point of view (e.g., McDougall et al., 1999), in which a symbol's efficiency is equated with an unequivocal interpretation (see Ng \& Chan, 2009). Regarding

Table 5 Symbols' frequency distribution according to meaning level across dimensions

\begin{tabular}{|c|c|c|c|c|c|c|c|c|c|c|c|c|c|c|c|c|c|c|c|c|c|c|}
\hline \multirow[t]{2}{*}{ Meaning } & \multicolumn{3}{|c|}{ Aesthetic Appeal } & \multicolumn{3}{|c|}{ Familiarity } & \multicolumn{3}{|c|}{ Visual Complexity } & \multicolumn{3}{|c|}{ Concreteness } & \multicolumn{3}{|c|}{ Valence } & \multicolumn{3}{|c|}{ Arousal } & \multicolumn{3}{|c|}{ Meaningfulness } & \multirow[t]{2}{*}{ Total } \\
\hline & $\mathrm{L}$ & M & $\mathrm{H}$ & $\mathrm{L}$ & M & $\mathrm{H}$ & $\mathrm{L}$ & M & $\mathrm{H}$ & $\mathrm{L}$ & M & $\mathrm{H}$ & $\mathrm{L}$ & M & $\mathrm{H}$ & $\mathrm{L}$ & M & $\mathrm{H}$ & $\mathrm{L}$ & M & $\mathrm{H}$ & \\
\hline Q1 & 82 & 56 & 7 & 133 & 12 & 0 & 80 & 42 & 23 & 123 & 22 & 0 & 29 & 105 & 11 & 23 & 112 & 10 & 120 & 25 & 0 & 145 \\
\hline Q2-Q3 & 33 & 172 & 110 & 20 & 129 & 166 & 172 & 134 & 9 & 14 & 93 & 208 & 46 & 114 & 155 & 18 & 187 & 110 & 6 & 96 & 213 & 315 \\
\hline Q4 & 6 & 40 & 94 & 0 & 3 & 137 & 95 & 45 & 0 & 0 & 2 & 138 & 23 & 19 & 98 & 4 & 40 & 96 & 0 & 0 & 140 & 140 \\
\hline Total & 121 & 268 & 211 & 153 & 144 & 303 & 347 & 221 & 32 & 137 & 117 & 346 & 98 & 238 & 264 & 45 & 339 & 216 & 126 & 121 & 353 & 600 \\
\hline
\end{tabular}

$N=600$ symbols. Levels across dimensions $\mathrm{L}=$ low; $\mathrm{M}=$ moderate; $\mathrm{H}=$ high. $\mathrm{Q} 1=$ low proportion of valid responses. Q2-Q3 = medium proportion of valid responses. Q4 = high proportion of valid responses 
the use of symbols in experimental paradigms to investigate other phenomena (e.g., evaluation processes), this plasticity may be an advantage by conferring flexibility to the materials.

The present article presents the subjective norms of symbols with relevance to the work of researchers in several areas of cognitive research (e.g., memory, perception, language, and decision making), as well as with potential use in more applied domains, such as communication, safety, and design. We consider that our database - LSD - constitutes a valuable addition to the existing pool of pretested pictorial materials that researchers recurrently need to use in their studies.

Author note R.R.S. is now at the Social Cognition Center Cologne, University of Cologne, Cologne, Germany. Part of this research was funded by Grant Number SFRH/BPD/73528/2010, awarded by Fundação para a Ciência e Tecnologia to the second author, and by a Marie Curie fellowship awarded to the last author (No. FP7-PEOPLE2013-CIG/631673). We thank Sandra Godinho, Daniel Santos, Inês Galamba Soares, Mafalda Visitação, Ana Roberto, André Prada, Ruben Trilho, and Ana Mota for their help in the data collection. We also thank Nuno Porto for his assistance in preparing the figures.

\section{References}

Adelman, J. S., \& Estes, Z. (2013). Emotion and memory: A recognition advantage for positive and negative words independent of arousal. Cognition, 129, 530-535. doi:10.1016/j.cognition.2013.08.014

Alario, F.-X., \& Ferrand, L. (1999). A set of 400 pictures standardized for French: Norms for name agreement, image agreement, familiarity, visual complexity, image variability, and age of acquisition. Behavior Research Methods, Instruments, \& Computers, 31, 531552. doi:10.3758/BF03200732

Angrilli, A., Cherubini, P., Pavese, A., \& Manfredini, S. (1997). The influence of affective factors on time perception. Perception \& Psychophysics, 59, 972-982. doi:10.3758/bf03205512

Arend, U., Muthig, K. P., \& Wandmacher, J. (1987). Evidence for global feature superiority in menu selection by icons. Behaviour and Information Technology, 6, 411-426. doi:10.1080/ 01449298708901853

Backs, R. W., da Silva, S. P., \& Han, K. (2005). A comparison of younger and older adults' Self-Assessment Manikin ratings of affective pictures. Experimental Aging Research, 31, 421-440. doi:10.1080/ 03610730500206808

Barchard, K., \& Williams, J. (2008). Practical advice for conducting ethical online experiments and questionnaires for United States psychologists. Behavior Research Methods, 40, 1111-1128. doi:10. 3758/BRM.40.4.1111

Bargh, J. A., \& Chartrand, T. L. (2000). The mind in the middle: A practical guide to priming and automaticity research. In H. T. Reis \& C. M. Judd (Eds.), Handbook of research methods in social and personality psychology (pp. 253-285). New York: Cambridge University Press.

Biederman, I. (1987). Recognition-by-components: A theory of human image understanding. Psychological Review, 94, 115-145. doi:10. 1037/0033-295x.94.2.115

Blees, G. J., \& Mak, W. M. (2012). Comprehension of disaster pictorials across cultures. Journal of Multilingual and Multicultural Development, 33, 699-716. doi:10.1080/01434632.2012.715798

Bonin, P., Peereman, R., Malardier, N., Méot, A., \& Chalard, M. (2003). A new set of 299 pictures for psycholinguistic studies: French norms for name agreement, image agreement, conceptual familiarity, visual complexity, image variability, age of acquisition, and naming latencies. Behavior Research Methods, Instruments, \& Computers, 35, 158-167. doi:10.3758/BF03195507

Bradley, M. M., \& Lang, P. J. (1999a). Affective norms for English words (ANEW): Stimuli, instruction manual and affective ratings (Technical Report C-1). Gainesville: University of Florida: Center for Research in Psychophysiology.

Bradley, M. M., \& Lang, P. J. (1999b). International affective digitized sounds (IADS): Stimuli, instruction manual and affective ratings (Technical Report B-2). Gainesville: University of Florida, Center for Research in Psychophysiology.

Bradley, M. M., Greenwald, M. K., Petry, M. C., \& Lang, P. J. (1992). Remembering pictures: Pleasure and arousal in memory. Journal of Experimental Psychology: Learning, Memory, and Cognition, 18, 379-390. doi:10.1037/0278-7393.18.2.379

Byrne, M. D. (1993). Using icons to find documents: Simplicity is critical. Proceedings of the INTERACT '93 and CHI '93 Conference on Human Factors in Computing Systems, 446-453. doi:10.1145/ 169059.169369

Cahill, M. (1975). Interpretability of graphic symbols as a function of context and experience factors. Journal of Applied Psychology, 60, 376-380. doi:10.1037/h0076624

Chan, A. H. S., \& Chan, K. W. L. (2013). Effects of prospective-user factors and sign design features on guessability of pharmaceutical pictograms. Patient Education and Counseling, 90, 268-275. doi: 10.1016/j.pec.2012.10.009

Chan, A. H. S., \& Ng, A. W. (2012). The guessing of mine safety signs meaning: Effects of user factors and cognitive sign features. International Journal of Occupational Safety and Ergonomics, 18, 195-208. doi:10.1080/10803548.2012.11076928

Chiu, S., Koong, C. S., \& Fan, S. H. (2012). Icon design principles for preschoolers: Implications derived from child development. Procedia: Social and Behavioral Sciences, 64, 228-237. doi:10. 1016/j.sbspro.2012.11.027

Christ, R. E., \& Corso, G. (1982). The effects of extended practice on the evaluation of visual display codes. Human Factors, 25, 71-84. doi: $10.1177 / 001872088302500107$

Colombetti, G. (2005). Appraising valence. Journal of Consciousness Studies, 12, 103-126.

Cycowicz, Y. M., Friedman, D., Rothstein, M., \& Snodgrass, J. G. (1997). Picture naming by young children: Norms for name agreement, familiarity, and visual complexity. Journal of Experimental Child Psychology, 65, 171-237. doi:10.1006/jecp.1996.2356

Dan-Glauser, E. S., \& Scherer, K. R. (2011). The Geneva Affective Picture Database (GAPED): A new 730-picture database focusing on valence and normative significance. Behavior Research Methods, 43, 468-477. doi:10.3758/s13428-011-0064-1

Dutch Center for Lexical Information. (1995). The CELEX lexical database. Nijmegen: Dutch Center for Lexical Information.

Ebner, N. C., Riediger, M., \& Lindenberger, U. (2010). FACES-A database of facial expressions in young, middle-aged, and older women and men: Development and validation. Behavior Research Methods, 42, 351-362. doi:10.3758/BRM.42.1.351

Figl, K., Mendling, J., \& Strembeck, M. (2013). The influence of notational deficiencies on process model comprehension. Journal of the Association for Information Systems, 14, 312-338.

Forsythe, A., Mulhern, G., \& Sawey, M. (2008). Confounds in pictorial sets: The role of complexity and familiarity in basic-level picture processing. Behavior Research Methods, 40, 116-129. doi:10.3758/ BRM.40.1.116

Frijda, N. H. (1986). The emotions. Cambridge: Cambridge University Press.

Garcia, M., Badre, A. N., \& Stasko, T. (1994). Development and validation of icons varying in their abstractness. Interacting with Computers, 6, 191-211. doi:10.1016/0953-5438(94)90024-8 
Garcia-Marques, T. (2005). Diferenciando "primação afectiva" de "primação cognitiva" [Distinguishing "affective priming" from “cognitive priming”]. Análise Psicológica, 4, 437-447. doi:10. 14417/ap.560

Garcia-Marques, T., Mackie, D. M., Claypool, H. M., \& Garcia-Marques, L. (2004). Positivity can cue familiarity. Personality and Social Psychology Bulletin, 30, 585-593. doi:10.1177/0146167203262856

Gerlach, C., \& Marques, J. F. (2014). Visual complexity exerts opposing effects on object categorization and identification. Visual Cognition, 22, 751-769. doi:10.1080/13506285.2014.915908

Goeleven, E., De Raedt, R., Leyman, L., \& Verschuere, B. (2008). The Karolinska Directed Emotional Faces: A validation study. Cognition and Emotion, 22, 1094-1118. doi:10.1080/02699930701626582

Green, A. J. K., \& Barnard, P. J. (1990). Iconic interfacing: The role of icon distinctiveness and fixed or variable screen locations. In D. Diaper, D. Gilmore, G. Cockton, \& B. Shackel (Eds.), HumanComputer Interaction -Interact' 90 (pp. 457-462). Amsterdam: Elsevier Science.

Grühn, D., \& Scheibe, S. (2008). Age-related differences in valence and arousal ratings of pictures from the International Affective Picture System (IAPS): Do ratings become more extreme with age? Behavior Research Methods, 40, 512-521. doi:10.3758/brm.40.2. 512

Harbeck, J. (2011). Index, icon, symbol: A tale of abduction. Indexer, 29, $157-160$.

Harmon-Jones, E., \& Allen, J. B. (2001). The role of affect in the mere exposure effect: Evidence from psychophysiological and individual differences approaches. Personality and Social Psychology Bulletin, 27, 889-898. doi:10.1177/0146167201277011

Hess, T. M., Waters, S. J., \& Bolstad, C. A. (2000). Motivational and cognitive influences on affective priming in adulthood. Journals of Gerontology, 55B, 193-204. doi:10.1093/geronb/55.4.p193

Huang, S.-C., Bias, R. G., \& Schnyer, D. (2015). How are icons processed by the brain? Neuroimaging measures of four types of visual stimuli used in information systems. Journal of the Association for Information Science and Technology, 66, 702-720. doi:10.1002/asi. 23210

Isherwood, S. J., McDougall, S. J., \& Curry, M. B. (2007). Icon identification in context: The changing role of icon characteristics with user experience. Human Factors, 49, 465-476. doi:10.1518/ $001872007 \times 200102$

Ito, T. A., Cacioppo, J. T., \& Lang, P. J. (1998). Eliciting affect using the International Affective Picture System: Trajectories through evaluative space. Personality and Social Psychology Bulletin, 24, 855879. doi:10.1177/0146167298248006

Johnson, K. D., Rao, H., Wintering, N., Dhillon, N., Hu, S., Zhu, S., . . Newberg, A. B. (2014). Pilot study of the effect of religious symbols on brain function: Association with measures of religiosity. Spirituality in Clinical Practice, 1, 82-98. doi:10.1037/scp0000015

Kučera, H., \& Francis, N. (1967). Computational analysis of present-day American English. Providence: Brown University Press.

Lang, P. J., Bradley, M. M., \& Cuthbert, B. N. (1998). International affective pictures system (IAPS): Digitized photographs, instruction manual and affective ratings (Technical Report A-6). Gainesville: University of Florida.

Lang, P. J., Bradley, M. M., \& Cuthbert, B. N. (2008). International affective picture system (IAPS): Affective ratings of pictures and instruction manual (Technical Report A-8). Gainesville: University of Florida.

Langner, O., Dotsch, R., Bijlstra, G., Wigboldus, D. J., Hawk, S. T., \& van Knippenberg, A. (2010). Presentation and validation of the Radboud Faces Database. Cognition and Emotion, 24, 1377-1388. doi:10.1080/02699930903485076

Lesch, M. F., Powell, W. R., Horrey, W. J., \& Wogalter, M. S. (2013). The use of contextual cues to improve warning symbol comprehension:
Making the connection for older adults. Ergonomics, 56, 1264 1279. doi:10.1080/00140139.2013.802019

Leung, R., McGrenere, J., \& Graf, P. (2011). Age-related differences in the initial usability of mobile device icons. Behaviour and Information Technology, 30, 629-642. doi:10.1080/ 01449290903171308

Libkuman, T. M., Otani, H., Kern, R., Viger, S. G., \& Novak, N. (2007). Multidimensional normative ratings for the International Affective Picture System. Behavior Research Methods, 39, 326-334. doi:10. 3758/bf03193164

Mandel, N., \& Johnson, E. J. (2002). When web pages influence choice: Effects of visual primes on experts and novices. Journal of Consumer Research, 29, 235-245. doi:10.1086/341573

Marchewka, A., Zurawski, L., Jednorog, K., \& Grabowska, A. (2013). The Nencki Affective Picture System (NAPS): Introduction to a novel standardized wide range high quality realistic pictures database. Behavior Research Methods, 46, 596-610. doi:10.3758/ s13428-013-0379-1

Massey, S. G. (2010). Valued differences or benevolent stereotypes? Exploring the influence of positive beliefs on anti-gay and antilesbian attitudes. Psychology \& Sexuality, 1, 115-130. doi:10. 1080/19419899.2010.484593

McDougall, S. J., \& Isherwood, S. (2009). What's in a name? The role of graphics, functions, and their interrelationships in icon identification. Behavior Research Methods, 41, 325-336. doi:10.3758/brm. 41.2.325

McDougall, S. J., \& Reppa, I. (2008). Why do I like it? The relationships between icon characteristics, user performance and aesthetic appeal. In Proceedings of the Human Factors and Ergonomics Society Annual Meeting (Vol. 52, pp. 1257-1261). New York, NY: Sage. doi:10.1177/154193120805201822

McDougall, S. J., Curry, M. B., \& de Bruijn, O. (1999). Measuring symbol and icon characteristics: Norms for concreteness, complexity, meaningfulness, familiarity, and semantic distance for 239 symbols. Behavior Research Methods, Instruments, \& Computers, 31, 487519. doi:10.3758/bf03200730

McDougall, S. J., de Bruijn, O., \& Curry, M. B. (2000). Exploring the effects of icon characteristics on user performance: The role of icon concreteness, complexity, and distinctiveness. Journal of Experimental Psychology: Applied, 6, 291-306. doi:10.1037/ 1076-898x.6.4.291

McDougall, S., Tyrer, V., \& Folkard, S. (2006). Searching for signs, symbols, and icons: Effects of time of day, visual complexity, and grouping. Journal of Experimental Psychology: Applied, 12, 118128. doi:10.1037/1076-898x.12.2.118

Monin, B. (2003). The warm glow heuristic: When liking leads to familiarity. Journal of Personality and Social Psychology, 85, 10351048. doi:10.1037/0022-3514.85.6.1035

Montagne, M. (2013). Pharmaceutical pictograms: A model for development and testing for comprehension and utility. Research in Social and Administrative Pharmacy, 9, 609-620. doi:10.1016/j.sapharm. 2013.04.003

Moors, A., De Houwer, J., Hermans, D., Wanmaker, S., van Schie, K., Van Harmelen, A. L., . . . Brysbaert, M. (2013). Norms of valence, arousal, dominance, and age of acquisition for 4,300 Dutch words. Behavior Research Methods, 45, 169-177. doi:10.3758/s13428012-0243-8

Moyes, J., \& Jordan, P. W. (1993). Icon design and its effect on guessability, learnability and experienced user performance. In J. D. Alty, D. Diaper, \& S. Guest (Eds.), People and computers VIII (pp. 49-59). Cambridge: Cambridge University Society.

Murphy, S. T., \& Zajonc, R. B. (1993). Affect, cognition, and awareness: Affective priming with optimal and suboptimal stimulus exposures. Journal of Personality and Social Psychology, 64, 723-739. doi:10. 1037/0022-3514.64.5.723 
Nakamura, C., \& Zeng-Treitler, Q. (2012). A taxonomy of representation strategies in iconic communication. International Journal of Human-Computer Studies, 70, 535-551. doi:10.1016/j.ijhcs.2012. 02.009

Ng, A. W. Y., \& Chan, A. H. S. (2007). The guessability of traffic signs: Effects of prospective-user factors and sign design features. Accident Analysis \& Prevention, 39, 1245-1257. doi:10.1016/j. aap.2007.03.018

Ng, A. W. Y., \& Chan, A. H. S. (2009). What makes an icon effective? AIP Conference Proceedings, 1089, 104-114. doi:10. 1063/1.3078113

Oh, K., Rogoff, A., \& Smith-Jackson, T. (2013). The effects of sign design features on bicycle pictorial symbols for bicycling facility signs. Applied Ergonomics, 44, 990-995. doi:10.1016/j.apergo. 2013.03.026

Osgood, C., Suci, G., \& Tannenbaum, P. (1957). The measurement of meaning. Urbana: University of Illinois.

Paivio, A., Clark, J. M., Digdon, N., \& Bons, T. (1989). Referential processing: Reciprocity and correlates of naming and imaging. Memory \& Cognition, 17, 163-174. doi:10.3758/bf03197066

Palma, T. A., Garrido, M. V., \& Semin, G. R. (2014). Situating person memory: The role of the visual context on memory for behavioral information. Journal of Experimental Social Psychology, 52, 32-43. doi:10.1016/j.jesp.2013.12.006

Phaf, R. H., \& Rotteveel, M. (2005). Affective modulation of recognition bias. Emotion, 5, 309-318. doi:10.1037/1528-3542.5.3.309

Prada, M., Cunha, C., Garcia-Marques, T., \& Rodrigues, D. (2010). Continuação do FIM - Normas de valência e familiaridade das imagens do Ficheiro de Imagens Multicategoriais [Continuing the FIM-Valence and Familiarity Norms for the Multicategory Image File]. Laboratório de Psicologia, 8, 185-211. doi:10.14417/lp.641

Proctor, R. W., \& Vu, K.-P. L. (1999). Index of norms and ratings published in the Psychonomic Society journals. Behavior Research Methods, Instruments, \& Computers, 31, 659-667. doi:10.3758/ bf03200742

Redondo, J., Fraga, I., Padrón, I., \& Piñeiro, A. (2008). Affective ratings of sound stimuli. Behavior Research Methods, 40, 784-790. doi:10. 3758/brm.40.3.784

Reppa, I., Playfoot, D., \& McDougall, S. J. P. (2008). Visual aesthetic appeal speeds processing of complex but not simple icons. In Proceedings of the Human Factors and Ergonomics Society Annual Meeting (Vol. 52, pp. 1155-1159). New York, NY: Sage. doi: $10.1177 / 154193120805201801$

Ribeiro, R. L., Pompéia, S., \& Bueno, O. F. A. (2005). Comparison of Brazilian and American norms for the International Affective Picture System (IAPS). Revista Brasileira de Psiquiatria, 27, 208215. doi:10.1590/s1516-44462005000300009

Rogers, Y. (1989). Icon design for the user interface. International Review of Ergonomics, 2, 129-154.

Rogers, Y., \& Oborne, D. J. (1987). Pictorial communication of abstract verbs in related to human-computer interaction. British Journal of Psychology, 78, 99-112. doi:10.1111/j.2044-8295.1987.tb02229.x

Rotteveel, M., \& Phaf, R. H. (2004). Loading working memory enhances affective priming. Psychonomic Bulletin \& Review, 11, 326-331. doi:10.3758/BF03196578

Sanfeliu, M. C., \& Fernandez, A. (1996). A set of 254 SnodgrassVanderwart pictures standardized for Spanish: Norms for name agreement, image agreement, familiarity, and visual complexity. Behavior Research Methods, Instruments, \& Computers, 28, 537555. doi:10.3758/bf03200541
Snodgrass, J. G., \& Corwin, J. (1988). Perceptual identification thresholds for 150 fragmented pictures from the Snodgrass and Vanderwart picture set. Perceptual and Motor Skills, 67, 3-36. doi:10.2466/pms.1988.67.1.3

Snodgrass, J. G., \& Vanderwart, M. (1980). A standardized set of 260 pictures: Norms for name agreement, image agreement, familiarity, and visual complexity. Journal of Experimental Psychology: Human Learning and Memory, 6, 174-215. doi:10.1037/02787393.6.2.174

Snodgrass, J. G., \& Yuditsky, T. (1996). Naming times for the Snodgrass and Vanderwart pictures. Behavior Research Methods, Instruments, \& Computers, 28, 516-536. doi:10.3758/bf03200540

Soares, A. P., Comesaña, M., Pinheiro, A. P., Simões, A., \& Frade, C. S. (2012). The adaptation of the Affective Norms for English Words (ANEW) for European Portuguese. Behavior Research Methods, 44, 256-269. doi:10.3758/s13428-011-0131-7

Soares, A. P., Pinheiro, A. P., Costa, A., Frade, C. S., Comesaña, M., \& Pureza, R. (2013). Affective auditory stimuli: Adaptation of the International Affective Digitized Sounds (IADS-2) for European Portuguese. Behavior Research Methods, 45, 1168-1181. doi:10. 3758/s13428-012-0310-1

Soares, A. P., Pinheiro, A. P., Costa, A., Frade, C. S., Comesaña, M., \& Pureza, R. (2014). Adaptation of the International Affective Picture System (IAPS) for European Portuguese. Behavior Research Methods. doi:10.3758/s13428-014-0535-2. Advance online publication.

Söderholm, C., Häyry, E., Laine, M., \& Karrasch, M. (2013). Valence and arousal ratings for 420 Finnish nouns by age and gender. PLoS ONE, 8, e72859. doi:10.1371/journal.pone.0072859

Stammers, R. B., \& Hoffman, J. (1991). Transfer between icon sets and ratings of icon concreteness and appropriateness. In Proceedings of the Human Factors and Ergonomics Society Annual Meeting (Vol. 35, pp. 354-358). Sage. doi:10.1177/154193129103500525

Stammers, R. B., George, D. A., \& Carey, M. S. (1989). An evaluation of abstract and concrete icons for a CAD package. In E. D. Megaw (Ed.), Contemporary ergonomics (pp. 416-421). London: Taylor \& Francis. doi:10.1080/00207548508928076

Stotts, D. B. (1998). The usefulness of icons on the computer interface: Effect of graphical abstraction and functional representation on experienced and novice users. In Proceedings of the Human Factors and Ergonomics Society 42nd Annual Meeting (pp. 453-457). Santa Monica: Human Factors and Ergonomics Society. doi:10.1177/ 154193129804200502

Székely, A., \& Bates, E. (2000). Objective visual complexity as a variable in studies of picture naming. CRL Newsletter, 12, 3-33.

Tijus, C., Barcenilla, J., Lavalette, B. C., \& Meunier, J.-G. (2007). The design, understanding and usage of pictograms. In D. Alamargot, $\mathrm{P}$. Terrier, \& J. M. Cellier (Eds.), Written documents in the workplace (pp. 17-31). Amsterdam: Elsevier. doi:10.1163/9789004253254 003

Wang, L., Chen, C.-W., \& Zhu, L. (2014). Picture norms for Chinese preschool children: Name agreement, familiarity, and visual complexity. PLoS ONE, 9, e90450. doi:10.1371/journal.pone.0090450

Warriner, A. B., Kuperman, V., \& Brysbaert, M. (2013). Norms of valence, arousal, and dominance for 13,915 English lemmas. Behavior Research Methods, 45, 1191-1207. doi:10.3758/s13428-012-0314-x

Wolff, J. S., \& Wogalter, M. S. (1998). Comprehension of pictorial symbols: Effects of context and test method. Human Factors, 40, 173186. doi:10.1518/001872098779480433

Zajonc, R. B. (1968). Attitudinal effects of mere exposure. Journal of Personality and Social Psychology, 9, 1-27. doi:10.1037/h0025848 